\title{
Psychological distress and stressful life events in pediatric complex regional pain syndrome
}

\author{
Julia Wager Ms Psychol ${ }^{1,2}$, Hannah Brehmer MD², Gerrit Hirschfeld Ms Psychol ${ }^{3}$, Boris Zernikow MD ${ }^{1,2}$
}

\begin{abstract}
J Wager, H Brehmer, G Hirschfeld, B Zernikow. Psychological distress and stressful life events in pediatric complex regional pain syndrome. Pain Res Manag 2015;20(4):189-194.

BACKGROUND: There is little knowledge regarding the association between psychological factors and complex regional pain syndrome (CRPS) in children. Specifically, it is not known which factors precipitate CRPS and which result from the ongoing painful disease.

OBJECTIVES: To examine symptoms of depression and anxiety as well as the experience of stressful life events in children with CRPS compared with children with chronic primary headaches and functional abdominal pain.

METHODS: A retrospective chart study examined children with CRPS $(n=37)$ who received intensive inpatient pain treatment between 2004 and 2010. They were compared with two control groups (chronic primary headaches and functional abdominal pain; each $n=37$ ), who also received intensive inpatient pain treatment. Control groups were matched with the CRPS group with regard to admission date, age and sex. Groups were compared on symptoms of depression and anxiety as well as stressful life events. RESULTS: Children with CRPS reported lower anxiety and depression scores compared with children with abdominal pain. A higher number of stressful life events before and after the onset of the pain condition was observed for children with CRPS.

CONCLUSIONS: Children with CRPS are not particularly prone to symptoms of anxiety or depression. Importantly, children with CRPS experienced more stressful life events than children with chronic headaches or abdominal pain. Prospective long-term studies are needed to further explore the potential role of stressful life events in the etiology of CRPS.
\end{abstract}

Key Words: Anxiety; Chronic pain; Complex regional pain syndrome; Depression; Pediatric pain; Psychological distress; Stressful life events

$\mathrm{C}$ omplex regional pain syndrome (CRPS) is increasingly recognized as a serious pain disorder in children and adolescents. CRPS is associated with strong physical impairments and appears to have unfavourable long-term outcomes in many affected children and adolescents $(1,2)$. Treating CRPS is challenging because there is little knowledge on the etiology and pathophysiology of this disorder. Several different pathophysiological factors of CRPS have been proposed, and include inflammatory processes, autoimmune responses, abnormal cytokine production, sympathetic-sensory disorders or functional changes in the central nervous system (3). Additionally, psychological distress, such as anxiety or depression, and psychosocial factors, such as stressful life events, are potential etiological factors for CRPS $(3,4)$. In the present study, we focus on the role of psychological distress and the experience of stressful life events in CRPS.

\section{La détresse psychologique et les événements stressants de la vie en cas d'algodystrophie chez les enfants}

HISTORIQUE : On ne sait pas grand-chose de l'association entre les facteurs psychologiques et l'algodystrophie chez les enfants. Notamment, on ne sait pas quels facteurs précipitent l'algodystrophie et quels facteurs découlent de la maladie douloureuse continue.

OBJECTIFS : Comparer les symptômes de dépression et d'anxiété et l'expérience des événements stressants de la vie chez les enfants présentant une algodystrophie à ceux d'enfants souffrant de céphalées chroniques primaires et de douleurs abdominales fonctionnelles.

MÉTHODOLOGIE : Les chercheurs ont effectué une étude rétrospective des dossiers pour évaluer des enfants présentant une algodystrophie $(n=37)$ qui avaient été hospitalisés pour recevoir un traitement intensif contre la douleur entre 2004 et 2010. Ils les ont comparés à deux groupes témoins (céphalées chroniques primaires et douleurs abdominales fonctionnelles; chacun $n=37$ ), également hospitalisés pour recevoir un traitement intensif contre la douleur. Les groupes témoins ont été jumelés au groupe d'algodystrophie en fonction de la date d'admission, de l'âge et du sexe. Les chercheur ont comparé les symptômes de dépression et d'anxiété et les événements stressants de la vie entre les divers groupes.

RÉSULTATS : Les enfants présentant une algodystrophie obtenaient des scores d'anxiété et de dépression inférieurs à ceux des enfants souffrant de douleur abdominale. Les chercheurs ont observé plus d'événements stressants de la vie avant et après la maladie responsable des douleurs chez les enfants présentant une algodystrophie.

CONCLUSIONS : Les enfants présentant une algodystrophie ne sont pas particulièrement enclins à des symptômes d'anxiété ou de dépression. Fait important, ils éprouvaient plus d'événements stressants de la vie que ceux souffrant de céphalées chroniques ou de douleurs abdominales. Des études prospectives à long terme s'imposent pour explorer davantage le rôle potentiel des événements stressants de la vie dans l'étiologie de l'algodystrophie.

It is indisputable that CRPS is associated with psychological distress, such as symptoms of depression or anxiety, and impairment in psychosocial functioning such as decreased quality of life and role functioning $(3,5-8)$. However, it is difficult to determine the extent to which impairment of emotional and psychosocial functioning is a result of ongoing pain and disability in children with CRPS, or whether these factors contribute to the development or maintenance of CRPS. Evidence from prospective studies in adults indicates that psychological distress does not cause CRPS $(3,7,9)$. As such, no prospective studies have investigated the association between psychological distress and CRPS in children. It may not be appropriate to apply findings from adult research to the etiology of CRPS in children, because CRPS in children presents differently than CRPS in adults $(1,10)$. Therefore, there may also be differences in the etiology of the disorder.

\footnotetext{
${ }^{1}$ German Paediatric Pain Centre, Children's and Adolescents' Hospital Datteln, Witten/Herdecke University; '2Department of Children's Pain Therapy and Paediatric Palliative Care, Witten/Herdecke University, Faculty of Health, School of Medicine; ${ }^{3}$ University of Applied Sciences Osnabrück, Germany

Correspondence: Dr. rer. nat. Dipl.-Psych. Julia Wager; German Paediatric Pain Centre, Children's Hospital Datteln; Dr.-Friedrich Steiner Str. 5; 45711 Datteln, Germany. Telephone 49-2363-975-184, fax 49-2363-975-181, e-mail j.wager@deutsches-kinderschmerzzentrum.de
} 
Some pediatric studies report comorbid psychiatric diagnoses in children with CRPS (eg, mood disorders) $(5,6)$. However, these studies do not compare CRPS patients with appropriate control groups. Thus, psychological distress resulting from ongoing pain and disability cannot be excluded. One study by Logan et al (11) implemented a control group design and found no differences in depression and anxiety scores among patients with CRPS, headaches, abdominal or back pain. Because children with CRPS are not more prone to psychological distress compared with children with other pain conditions, psychological distress may result from the pain experience and may not be associated with the development of CRPS.

Stressful life events are one factor that may increase an adult's risk for developing CRPS (12). Sherry and Weisman (13) discussed stressful live events occurring before the onset of CRPS in children. However, to our knowledge, the association between stressful life events and the onset of CRPS has not been systematically examined in children. Investigating stressful life events that occur before the onset of CRPS may provide important clues to their role in the etiology of CRPS.

The present study aimed to investigate the specific role of psychological distress and the experience of stressful life events for the development of pediatric CRPS by comparing these factors between children with CRPS and children with equally severe chronic primary headache and functional abdominal pain. We expected no differences in psychological distress among the groups (11) but a higher impact of stressful life events before the onset of CRPS when compared with the headache and abdominal pain groups.

\section{Procedure}

\section{METHODS}

The present retrospective study included children and adolescents who received an intensive multimodal inpatient pain treatment at the German Paediatric Pain Centre between 2004 and 2010. Participants had been diagnosed with one of three pain conditions: CRPS I, chronic primary headache or functional abdominal pain. All children with CRPS $(n=37)$ fulfilled the International Association for the Study of Pain diagnostic criteria for CRPS I (14). Patients with primary headache $(n=37)$ and functional abdominal pain $(n=37)$ who received intensive inpatient treatment were included in the study as control groups because they had comparable pain severity levels. Control groups were matched to the CRPS group on their admission dates, age and sex.

\section{Measures}

Data were collected using a retrospective chart study design. Pain characteristics were measured by the German Pain Questionnaire for Children and Adolescents $(15,16)$. This questionnaire is a comprehensive, multidimensional tool that allows for a structured assessment of biopsychosocial pain parameters (also available in English [16]). Pain intensity, school absence and pain-related disability were evaluated. The average pain intensity over the past four weeks was reported on a numerical rating scale (NRS; 0 = 'no pain' to 10 = 'worst pain'). School absence was assessed by the number of days absent from school in the past four weeks (range zero to 20). The Paediatric Pain Disability Index was used to measure pain-related disability in everyday life (17). This brief 12 -item tool has been validated for pediatric patients with chronic pain and has good internal consistency (Cronbach's alpha $=0.87$ ) as well as convergent validity $(17)$. The total score ranges between 12 and 60; higher Paediatric Pain Disability Index scores reflect higher pain-related disability, while lower scores reflect less disability.

Depression symptoms were assessed with the Depression Inventory for Children and Adolescents (18), which is the German version of the Children's Depression Inventory (19). The Depression Inventory is a one-dimensional self-report measure with 26 items. It has good reliability (Cronbach's alpha $=0.84$ ) as well as good discriminant and convergent validity (18). The Anxiety Questionnaire for Pupils (20) assesses general anxiety, fear of examinations and school aversion with 50 self-report items. It demonstrates good reliability (Cronbach's alpha range from 0.73 to 0.85 ) and validity (20). Normed scores based on a German community sample (standardized T-scores with a mean [ $\pm \mathrm{SD}]$ of $50 \pm 10$ ) are available for both the depression and anxiety measures.

Stressful life events were classified by the Social Readjustment Rating Scale by Coddington (21). This scale has been translated with a cross-cultural translation method (22) and has been validated in a clinical sample of pediatric pain patients (23). Stressful life events are defined as "those events that require a readjustment on the part of the individual, a change in his life" (24). This definition includes events with positive (eg, outstanding personal achievement) and negative connotations (eg, serious illness requiring hospitalization of a parent). In the present study, 40 life events were evaluated. The number of stressful life events were counted as well as the severity, ie, each life event requires a different level of adjustment, which is quantified in a numerical value of 'life change units' (LCUs). The classification of stressful life events differs according to age group. In the present study, three different age groups were used: elementary school $(<12$ years of age), junior high school (12 to 16 years of age) and senior high school ( $>16$ years of age). Information about life events was gathered from the following chart documents: the standardized doctor's letter with a detailed description of the child's and family's history, notes taken at admission and notes taken during multiprofessional ward rounds.

\section{Statistics}

ANOVAs were computed to compare the three groups (CRPS, headaches, abdominal pain) with regard to continuous variables, including pain intensity, pain disability, school absence, pain onset, depression and anxiety scores as well as the number and the severity (LCU) of life events (before and after pain onset). A sensitivity analysis ( $G^{*}$ Power) revealed that an ANOVA can detect a medium to large effect $\left(\right.$ eta $^{2}=0.125$ ) with a significance level of $\mathrm{P}=0.05$ and a power of $95 \%$ in the present study sample $(n=111)$. Post hoc pairwise comparisons were calculated for significant results and adjusted with the Bonferroni correction. Effect sizes for significant group comparisons are reported to aid interpretability of results (eta ${ }^{2}>0.01$ to $0.06=$ small; $>0.06$ to $0.14=$ medium; >0.14 = large effect) (25).

Additional analyses of life events were conducted for positive and negative events. Not all events could be clearly categorized as positive or negative (eg, change in parents' financial status, marriage of parent to step-parent). These items were excluded in further analyses. In total, five positive events and 27 negative events were included. Additional analyses were conducted for family-related events (eg, divorce of parents; total number of items $=23$ ) or extrafamily events, ie, events occurring outside the family system (eg, change in child's acceptance by peers; total number of items $=17)(26)$.

All analyses were conducted using SPSS version 22.0 (IBM Corporation, USA) for Windows (Microsoft Corporation, USA).

\section{Patients}

\section{RESULTS}

Between October 2004 and September 2010, 37 CRPS patients were treated in an intensive multidisciplinary inpatient pain program at the German Paediatric Pain Centre and were included in the present study. CRPS patients were mostly female $(95 \%)$ and had a mean $( \pm S D)$ age of $14 \pm 2.5$ years (range 9.5 to 19.6 years). Two age- and sex-matched control groups with chronic primary headaches $(n=37)$ and functional abdominal pain $(n=37)$ were also included in the study. The three groups did not differ according to age or sex $(\mathrm{P}>0.05)$.

In CRPS patients, the upper limb was affected in 17 children (46\%), the lower limb in 15 children $(40.5 \%)$, and the upper and lower limbs in five children (13.5\%). A total of 31 children described minor injuries before the onset of their CRPS and six children did not clearly remember the presence of an initiating noxious event. 
TABLE 1

Pain characteristics in complex regional pain syndrome (CRPS), headaches and abdominal pain

\begin{tabular}{|c|c|c|c|c|c|c|}
\hline & CRPS & Headaches & Abdominal pain & $\mathbf{F}$ & $\mathbf{P}$ & eta $^{2}$ \\
\hline Maximum pain (NRS 0-10) & $9.1 \pm 0.9$ & $8.7 \pm 1.8$ & $8.7 \pm 1.7$ & 0.799 & 0.452 & - \\
\hline Average pain (NRS 0-10) & $7.8 \pm 1.5^{\ddagger}$ & $6.6 \pm 2.1 \S$ & $6.4 \pm 2.2^{\S}$ & 5.502 & 0.005 & 0.094 \\
\hline Pain disability, P-PDI* & $37.2 \pm 10.5$ & $41.7 \pm 10.8$ & $38.9 \pm 9.8$ & 1.765 & 0.176 & - \\
\hline School absence $^{\dagger}$ & $5.3 \pm 7.0$ & $6.4 \pm 6.1$ & $6.1 \pm 5.1$ & 0.333 & 0.717 & - \\
\hline Duration of pain, months & $8.8 \pm 9.2^{\ddagger}$ & $24.9 \pm 22.5^{\S}$ & $25.4 \pm 27.0$ & 7.444 & 0.001 & 0.125 \\
\hline
\end{tabular}

Bonferroni correction for post hoc analysis; within rows, means with different superscripts differ significantly. ${ }^{*} H i g h e r$ scores on the Paediatric Pain Disability Index (P-PDI) (17) indicate higher disability (range 12 to 60); ${ }^{\dagger}$ Days absent from school in the past four weeks (range 0 to 20). NRS Numerical rating scale

TABLE 2

Psychological distress in complex regional pain syndrome (CRPS), headaches and abdominal pain

\begin{tabular}{lllcccc}
\hline & CRPS & Headaches & Abdominal pain & F & P & eta $^{2}$ \\
\hline General anxiety* $^{*}$ & $49.4 \pm 11.5^{\ddagger}$ & $53.3 \pm 12.2^{\ddagger \S}$ & $57.4 \pm 13.2^{\S}$ & 3.517 & 0.033 & 0.067 \\
Fear of examination $^{*}$ & $50.0 \pm 13.9$ & $48.3 \pm 11.6$ & $51.9 \pm 11.3$ & 0.693 & 0.503 & - \\
School aversion* $^{*}$ & $44.2 \pm 10.2^{\ddagger}$ & $49.9 \pm 11.2^{\ddagger \S}$ & $53.0 \pm 11.8^{\S}$ & 5.353 & 0.006 & 0.100 \\
Depression $^{\dagger}$ & $52.8 \pm 11.2^{\ddagger}$ & $54.3 \pm 11.4^{\ddagger \S}$ & $60.5 \pm 14.0^{\S}$ & 3.795 & 0.026 & 0.071
\end{tabular}

Bonferroni correction for post hoc analysis; within rows, means with different superscripts differ significantly. *Assessed by the Anxiety Questionnaire for Pupils (20); ${ }^{\dagger}$ Assessed by the Depression Inventory for Children and Adolescents (18)

Children with CRPS, chronic primary headaches and functional abdominal pain did not differ in maximal pain intensity, pain disability or school absence $(\mathrm{P}>0.05)$ (Table 1$)$. The average pain intensity was significantly higher in children with CRPS compared with headache and abdominal pain patients $\left(F[2,106]=5.502 ; \mathrm{P}=0.005\right.$, eta $\left.{ }^{2}=0.094\right)$. At the time of hospital admission, children with CRPS had a significantly shorter pain duration compared with both other groups $\left(\mathrm{F}[2,104]=7.444 ; \mathrm{P}=0.001\right.$, eta $\left.{ }^{2}=0.125\right)$.

\section{Psychological distress}

Patients with CRPS, chronic primary headaches and functional abdominal pain reported different levels of general anxiety, school aversion and depression (Table 2). In all comparisons, children with abdominal pain had significantly higher values compared with CRPS patients. Children with headaches did not differ from those with CRPS and abdominal pain.

\section{Stressful life events}

The number of stressful life events before the onset of pain differed among groups $\left(\mathrm{F}[2,108]=3.218 ; \mathrm{P}=0.044 ;\right.$ eta $\left.^{2}=0.056\right)$. Children with CRPS experienced a mean of $1.9 \pm 1.52$ stressful life events, children with headaches experienced $1.1 \pm 1.08$ and children with abdominal pain experienced 1.6 \pm 1.26 (Figure 1A). The difference of the number of stressful life events between children with CRPS and those with headaches was statistically significant. Additionally, CRPS patients experienced more stressful life events after the onset of the pain condition compared with children with chronic primary headaches and functional abdominal pain $(F[2,108]=13.734$; $\mathrm{P}<0.01 ;$ eta $^{2}=0.203$ ).

Before the onset of pain, children with CRPS and abdominal pain experienced more event-related stress, ie, more LCUs, than children with headaches. However, statistical analyses were not significant $(\mathrm{F}[2$, $108]=2.848, P=0.062$; Figure 1B). LCUs after the onset of pain were much higher in patients with CRPS compared with the other two groups $\left(\mathrm{F}[2,108]=20.715 ; \mathrm{P}<0.001 ; \mathrm{eta}^{2}=0.277\right)$.

Additional analyses of stressful life events

A closer look at positive and negative life events before the onset of pain revealed that no positive life events were documented in the entire sample. A comparison of negative life events among groups showed that children with CRPS had significantly more negative life events (1.6 \pm 1.2$)$ than children with headaches (headaches, 0.9 \pm 0.9 ; abdominal pain, $1.3 \pm 1.1 ; \mathrm{F}[2,108]=4.345 ; \mathrm{P}=0.015$; $\left.\mathrm{eta}^{2}=0.074\right)$.

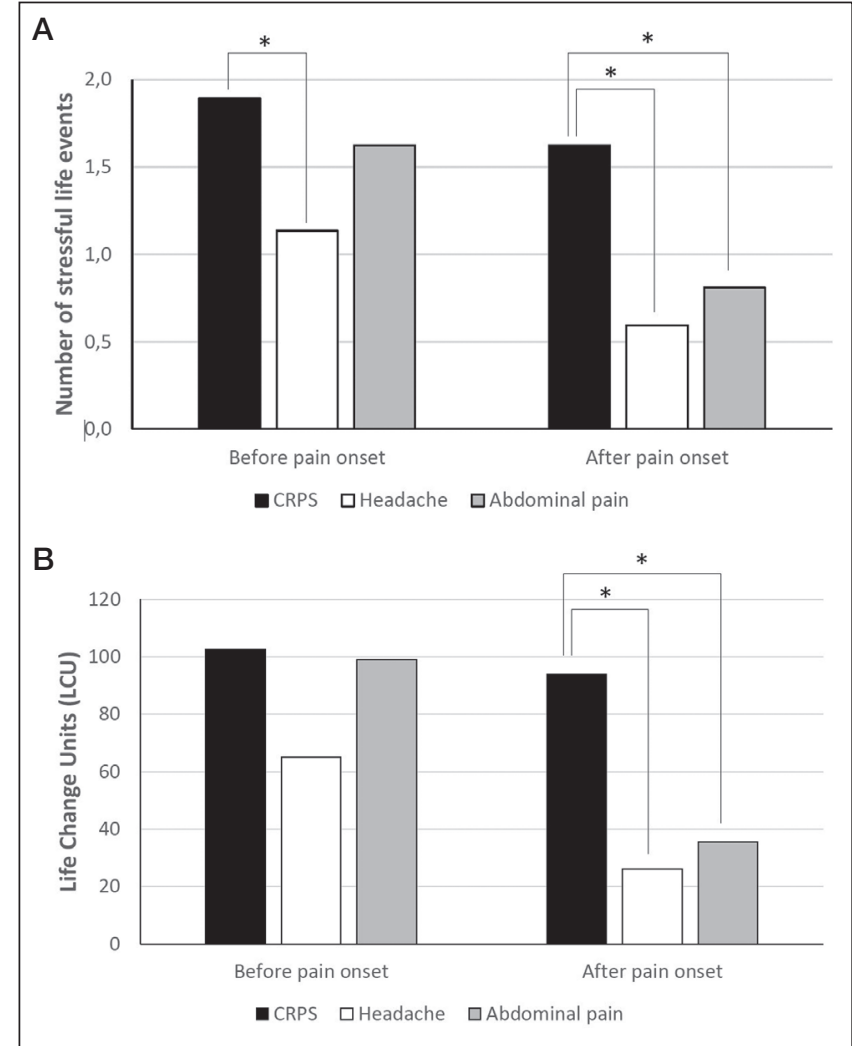

Figure 1) Stressful life events. A Number of stressful life events; B Life change units (overall severity of stressful life events). *Significant difference between groups (Bonferroni post hoc comparison)

Finally, life events were split into events that were related to and not related to family relations. Children with CRPS had significantly more stressful family-related life events $(1.5 \pm 1.3)$ than children with headaches (headaches, $0.7 \pm 0.8$; abdominal pain, $1.0 \pm 1.1$ ) before onset of pain $\left(F[2,108]=4.793 ; \mathrm{P}=0.010\right.$; eta $\left.{ }^{2}=0.082\right)$. Stressful nonfamily life events did not differ among groups (CRPS, $0.4 \pm 0.6$; headaches, $0.5 \pm 0.6$; abdominal pain, $0.6 \pm 0.8 ; F[2,108]=0.854$; $\mathrm{P}=0.428)$. 


\section{DISCUSSION}

There is little evidence for the role of depression, anxiety and stressful life events in the etiology of CRPS in children and adolescents. The present study investigated these psychological factors among pediatric patients with CRPS compared with pediatric patients with chronic primary headaches and functional abdominal pain who experienced comparable pain severity.

\section{Psychological distress}

Contrary to our hypotheses, depression and anxiety scores were lower in children with CRPS compared with children with functional abdominal pain. This finding challenges the etiological role of depression and anxiety in pediatric CRPS. At the same time, it demonstrates that the heavy burden of disease in CRPS patients (ie, physical changes, functional deficiencies and, often, a relatively long history of uncertainty regarding diagnosis) does not manifest in internalizing problems. We can only speculate about reasons for this finding and offer several interpretations. First, having a chronic disease increases the risk for anxious and depressive symptoms (27). Assuming that a longer course of disease increases this risk, children with CRPS have a lower risk to develop these symptoms because many have a shorter pain history compared with children with abdominal pain and headaches (28). This, however, does not explain why children with headaches only trended toward reporting a higher number of internalizing symptoms; this was not statistically significant. Possibly, the difference did not reach significance due to a relatively small sample size. Second, the findings of less internalizing symptoms in children with CRPS may also be explained by reactions of the social environment, eg, the school environment. Teachers often have a dualistic view on chronic pain and attribute it either to physical or psychological causes (29). Research shows that teachers tend to react more positively toward students with chronic pain if they attribute the pain to a physical etiology (29); ie, teachers offer more instrumental support and show more sympathy for the student. Because CRPS is associated with visible changes in appearance, such as edema or coloured skin changes, a physical attribution by the teacher may be more likely than in children with 'invisible' headaches or abdominal pain. As a result, CRPS patients may receive more support from their teachers and believe that they are treated fairly. This kind of reaction may not be limited to teachers but may also manifest in others within the patients' social environment. Therefore, patients with CRPS may not display the degree of reactive psychological distress demonstrated in the abdominal pain group. However, this interpretation again does not explain the nonsignificant difference between CRPS and headache patients. If headache patients and CRPS patients truly do not differ in their level of psychological distress and the comparison did not fail to reach significance due to the small sample size, anxiety and depression may be a specific etiological and/or maintaining factor in functional abdominal pain (30), but not in CRPS or chronic primary headaches.

Logan et al (11) also compared psychological distress in CRPS patients with other chronic pain conditions (headache, abdominal pain, back pain) in a similar study design. They did not find any differences between pain groups; ie, CRPS patients were as psychologically distressed as children with other pain conditions. Compared with our findings, the differences could be explained by the pain severity of the patient groups. In the study by Logan et al (11), CRPS patients had higher pain-related disabilities compared with headache and back pain patients. School absence was significantly higher in abdominal pain and headache patients compared with CRPS patients. In our study, patients did not differ on pain disability, school absence or maximal pain intensity. The similar levels of pain severity may be because all children qualified for and received an intensive multiprofessional inpatient treatment.

Taken together, Logan et al (11) and our study results suggest that CRPS patients are not more psychologically impaired compared with children with other chronic pain conditions. These results dispute the idea that severe psychological distress is a specific vulnerability factor for CRPS. However, studies often measure psychological distress after the onset of pain. Thus, evidence for this assumption is relatively weak. Unfortunately, given the low incidence of CRPS, it is difficult to conduct prospective studies on this condition.

\section{Stressful life events}

The role of stressful life events in the development of CRPS has long been discussed (12). In adults, stressful life events appear to be associated with the development of CRPS I (12). An observational study of children (13) described one major or several minor stressful events before the onset of CRPS. Our study showed that children with CRPS experienced more stressful life events before the onset of the pain compared with children with chronic primary headaches.

Studies in the general population show that the occurrence of stressful life events is associated with age (24). A peak in stressful life events emerges between six and seven years of age when the child starts school; a second, much larger peak in stressful life events occurs between the ages of 12 to 14 years at the beginning of puberty when turmoil increases (24). During this time, the child expands and changes her/his social sphere, which increases the number of life events, both positive and negative, and requires increased readjustment. In the present study, the average age of children at the onset of CRPS is approximately 13 years $(13.4 \pm 2.4$ years $)$. At this age, children are likely to experience an increase in life events. Children with headaches and abdominal pain are younger at the onset of pain (headaches, $12.1 \pm 2.7$ years; abdominal pain, $11.9 \pm 3.2$ years).

We found that family-related stressful events occured more often in CRPS patients. Although this has not previously been systematically investigated, family problems have been reported in previous studies on pediatric CRPS. Kachko et al (31) reported migration history, low socioeconomic status, divorce, chronic physical and mental conditions in parents or siblings, and inappropriate parenting behaviour, such as overprotective and controlling behaviour, in CRPS patients. In addition, Sherry et al (13) described difficult family environments in CRPS patients: either a very close relationship between parent(s) and child, or a bonded parental relationship for which the child often felt responsible. The impact of family events has a higher impact in younger children (21). Thus, difficult family environments established early in life over a longer time period may be permanent stressors. Along these lines, additional stressors that occur during puberty may be the straw that breaks the camel's back.

If stressors are important in the etiology of CRPS, they may also be important in the maintenance of the condition. In this sense, CRPS patients report a high number of stressful life events after the onset of pain. Additionally, in most children with CRPS, at least one of the stressors was having a visible deformity or not attending an extracurricular activity in which the child likes to be involved. These factors may partially explain the difficult treatment and high relapse rates in children with CRPS (1).

In summary, our results suggest that stressful life events may be one of several etiological factors for developing or maintaining CRPS. General health research has also demonstrated that stressful life events are associated with the etiology of illness (24). However, the present study design has several methodological limitations; therefore, results should be interpreted with care. More studies are needed to make conclusions on the etiological role of stressful life events.

One idea on how stressful life events may influence the development of CRPS is that they may alter the brain and make it more susceptible to develop a CRPS after a (minor) physical trauma. Several studies have shown that early stressful life events (eg, sexual, physical or emotional abuse, emotional or physical neglect as well as parental loss) lead to various neurobiological changes of the brain (32-34). These structural changes make the individual more prone to develop depression and a number of other disorders, such as chronic fatigue syndrome or dissociative disorder, later in life $(32,33,35)$. The risk for developing a mental disorder is modulated by numerous environmental factors, genotypes and epigenetic processes (36). One of the 
neurobiological changes after early life stress is an altered or increased brain connectivity $(37,38)$, which has also been observed in children with CRPS and may be partially reversed following successful treatment $(39,40)$. Clearly, a multifactorial disease model is needed to explain the development and maintenance of CRPS (41). Thus, stressful life events may predispose to develop CRPS later on in life, but this is neither a necessary nor a sufficient requirement. Altered brain anatomy and function due to stressful life events may be one link between psychological and biological aspects of the condition. These neurobiological changes may also occur in stressful life events that may be less obvious than abuse or neglect.

\section{Limitations}

Data for the present study were collected retrospectively. Additionally, critical life events were extracted from medical charts and not directly from patients. This procedure may cause reporting bias; eg, no positive life events were documented in the charts. In addition to reporting bias for negative events, many children may have not reported events that did not appear to be important to them in the context of their pain condition. For future studies, a systematic assessment of events is

\section{REFERENCES}

1. Tan EC, Zijlstra B, Essink ML, Goris RJ, Severijnen RS. Complex regional pain syndrome type I in children. Acta Paediatr 2008;97:875-9.

2. Wilder RT. Management of pediatric patients with complex regional pain syndrome. Clin J Pain 2006;22:443-8.

3. Borchers AT, Gershwin ME. Complex regional pain syndrome: A comprehensive and critical review. Autoimmun Rev 2014;13:242-65.

4. Geertzen JH, de Bruijn-Kofman AT, de Bruijn HP, van de Wiel HB, Dijkstra PU. Stressful life events and psychological dysfunction in complex regional pain syndrome type I. Clin J Pain 1998;14:143-7.

5. Brooke V, Janselewitz S. Outcomes of children with complex regional pain syndrome after intensive inpatient rehabilitation. PM R 2012;4:349-54.

6. Cruz N, O'Reilly J. Emotional and neuropsychological profiles of children with complex regional pain syndrome type-1 in an inpatient rehabilitation setting. Clin J Pain 2011;27:27.

7. Lohnberg JA, Altmaier EM. A review of psychosocial factors in complex regional pain syndrome. J Clin Psychol Med Settings 2013;20:247-54.

8. Lynch ME. Psychological aspects of reflex sympathetic dystrophy: A review of the adult and paediatric literature. Pain 1992;49:337-47.

9. Beerthuizen A, Stronks DL, Huygen FJPM, Passchier J, Klein J, Spijker A. The association between psychological factors and the development of complex regional pain syndrome type 1 (CRPS1) A prospective multicenter study. Eur J Pain 2011;15:971-5.

10. Logan DE, Carpino EA, Chiang G, et al. A day-hospital approach to treatment of pediatric complex regional pain syndrome: Initial functional outcomes. Clin J Pain 2012;28:766-74.

11. Logan DE, Williams SE, Carullo VP, Claar RL, Bruehl S, Berde CB. Children and adolescents with complex regional pain syndrome: More psychologically distressed than other children in pain? Pain Res Manag 2013;18:87-93.

12. Beerthuizen A, van't Spijker A, Huygen FJ, Klein J, de Wit R. Is there an association between psychological factors and the complex regional pain syndrome type 1 (CRPS1) in adults? A systematic review. Pain 2009;145:52-9.

13. Sherry DD, Weisman R. Psychologic aspects of childhood reflex neurovascular dystrophy. Pediatrics 1988;81:572-8.

14. Merskey H, Bogduk N. Classification of Chronic Pain. IASP Task Force on Taxonomy. Seattle: IASP Press, 1994.

15. Schroeder S, Hechler T, Denecke H, et al. [German Pain Questionnaire for Children, Adolescents and Parents (DSF-KJ) A multimodal questionnaire for diagnosis and treatment of children and adolescents suffering from chronic pain]. Schmerz 2010;24:23-37.

16. Dobe M, Zernikow B. Practical Treatment Options for Chronic Pain in Children and Adolescents: An Interdisciplinary Therapy Manual. Dobe M, Zernikow B, eds. Berlin, Heidelberg: Springer, 2013.

17. Hübner B, Hechler T, Dobe M, et al. [Pain-related disability in adolescents suffering from chronic pain: Preliminary examination of the Pediatric Pain Disability Index (P-PDI)]. Schmerz 2009;23:20-32. needed to rule out these limitations. The cross-sectional study design does not provide a final conclusion, but rather a careful approximation of the etiological role of depression, anxiety and stressful life events in the development of CRPS. Prospective studies are needed to reach a final conclusion.

\section{CONCLUSION}

Psychological distress does not appear to play a role in the etiology of CRPS in children. Rather, the experience of stressful events seems to be a factor that precipitates CRPS. Although CRPS is a highly disabling condition with an uncertain outcome, children with this disease do not experience higher levels of psychological distress when compared with patients with other chronic pain conditions. Further research, specifically prospective long-term studies, is needed to further explore the potential role of psychological distress and stressful life events in the etiology and maintenance of CRPS.

DISCLOSURES: The authors have no conflicts of interest to declare.

18. Stiensmeier-Pelster J, Schürmann M, Duda K. [Depression inventory for children and adolescents]. Göttingen: Hogrefe, 2000.

19. Kovacs M. Rating scales to assess depression in school-aged children. Acta Paedopsychiatrica 1981;46:305-15.

20. Wieczerkowski W, Nickel H, Janowksi A, Fittkau B, Rauer W. [Anxiety questionnaire for pupils]. Göttingen: Westermann, 1981.

21. Coddington RD. The significance of life events as etiologic factors in the diseases of children I - A survey of professional workers. J Psychosom Res 1972;16:205-13.

22. Beaton DE, Bombardier C, Guillemin F, Ferraz MB. Guidelines for the process of cross-cultural adaptation of self-report measures. Spine 2000;24:3186-91.

23. Bauer K. Kritische Lebensereignisse bei Jugendlichen mit chronischen Schmerzen: Auswirkungen auf den SchmerztherapieOutcome: Ruhr University Bochum, 2010.

24. Coddington RD. The significance of life events as etiologic factors in the diseases of children. II. A study of a normal population. J Psychosom Res 1972;16:205-13.

25. Cohen J. Statistical power analysis for the behavioral sciences. Cohen J, ed. New Jersey: Lawrence Erlbaum Associates, 1988.

26. Villalonga-Olives E, Rojas-Farreras S, Vilagut G, et al. Impact of recent life events on the health related quality of life of adolescents and youths: The role of gender and life events typologies in a follow-up study. Health Qual Life Outcomes 2010;8:71-9.

27. Ferro MA, Boyle MH. The impact of chronic physical illness, maternal depressive symptoms, family functioning, and self-esteem on symptoms of anxiety and depression in children. J Abnorm Child Psychol 2014:1-11.

28. DeGood DE, Cundiff GW, Adams LE, Shutty Jr MS. A psychosocial and behavioral comparison of reflex sympathetic dystrophy, low back pain and headache patients. Pain 1993;54:317-22.

29. Logan DE, Catanese SP, Coakley RM, Scharff L. Chronic pain in the classroom: Teachers' attributions about the causes of chronic pain. J Sch Health 2007;77:248-56.

30. Campo JV, Bridge J, Ehmann M, et al. Recurrent abdominal pain, anxiety, and depression in primary care. Pediatrics 2004;113:817-24.

31. Kachko L, Efrat R, Ben Ami S, Mukamel M, Katz J. Complex regional pain syndromes in children and adolescents. Pediatr Int 2008;50:523-7.

32. Kempke S, Luyten P, De Coninck S, Van Houdenhove B, Mayes LC, Claes S. Effects of early childhood trauma on hypothalamic-pituitary-adrenal (HPA) axis function in patients with chronic fatigue syndrome. Psychoneuroendocrinology 2015;52:14-21.

33. Nemeroff CB. Neurobiological consequences of childhood trauma. J Clin Psychiatry 2004;65(Suppl 1):18-28.

34. Heim CM, Mayberg HS, Mletzko T, Nemeroff CB, Pruessner JC. Decreased cortical representation of genital somatosensory field after childhood sexual abuse. Am J Psychiatry 2013;170:616-23.

35. Chalavi S, Vissia EM, Giesen ME, et al. Abnormal hippocampal morphology in dissociative identity disorder and post-traumatic 
stress disorder correlates with childhood trauma and dissociative symptoms. Hum Brain Mapp 2015;36:1692-704.

36. Hornung OP, Heim CM. Gene-environment interactions and intermediate phenotypes: Early trauma and depression. Front Endocrinol (Lausanne) 2014:5:14.

37. Dean AC, Kohno M, Hellemann G, London ED. Childhood maltreatment and amygdala connectivity in methamphetamine dependence: A pilot study. Brain Behav 2014;4:867-76.

38. Birn RM, Patriat R, Phillips ML, Germain A, Herringa RJ. Childhood maltreatment and combat posttraumiatic stress differentially predict fear-realted fronto-subcortical connectivity. Depress Anxiety 2014;31:880-92.

39. Becerra L, Sava S, Simons LE, et al. Intrinsic brain networks normalize with treatment in pediatric complex regional pain syndrome. Neuroimage Clin 2014;6:347-69.

40. Linnman C, Becerra L, Lebel A, Berde C, Grant PE, Borsook D. Transient and persistent pain induced connectivity alterations in pediatric complex regional pain syndrome. PloS One 2013;8:e57205.

41. Bruehl S, Chung OY. Psychological and behavioral aspects of complex regional pain syndrome management. Clin J Pain 2006;22:430-7. 


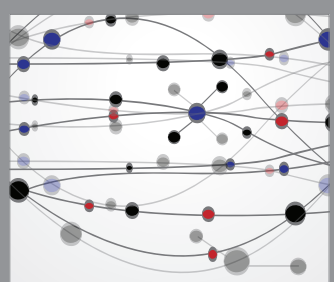

The Scientific World Journal
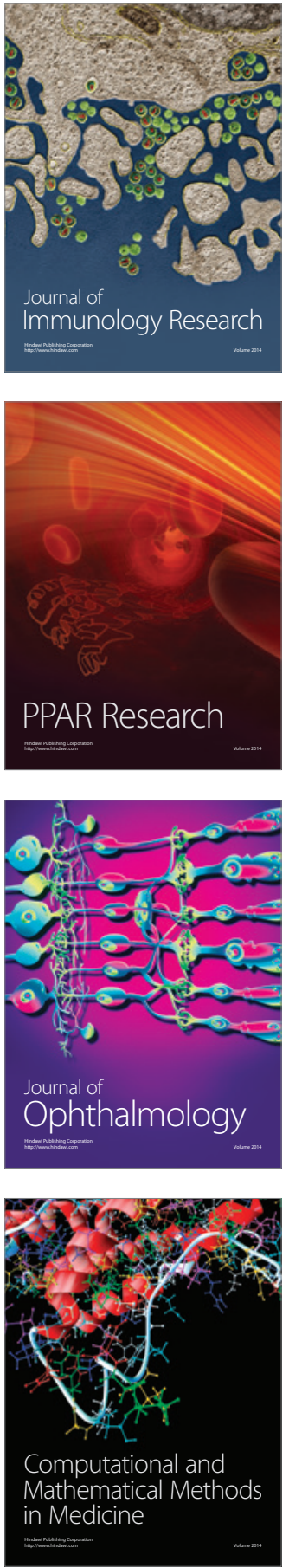

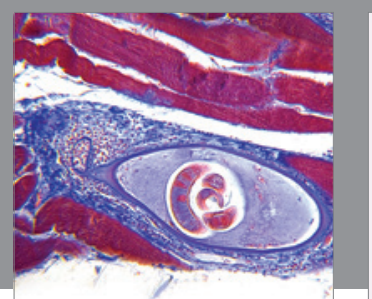

Gastroenterology Research and Practice

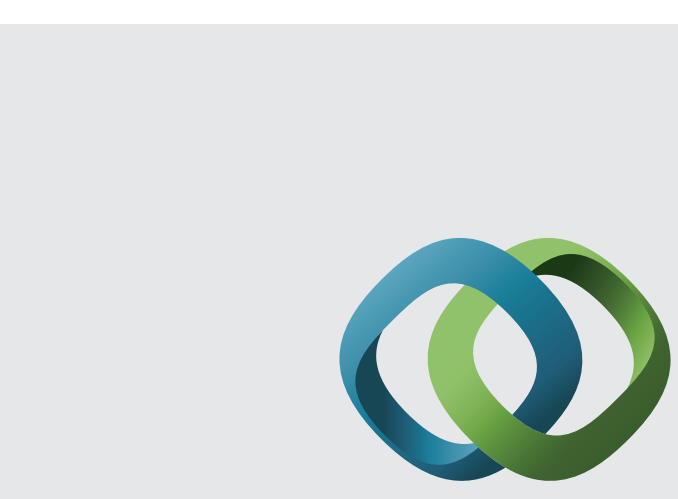

\section{Hindawi}

Submit your manuscripts at

http://www.hindawi.com
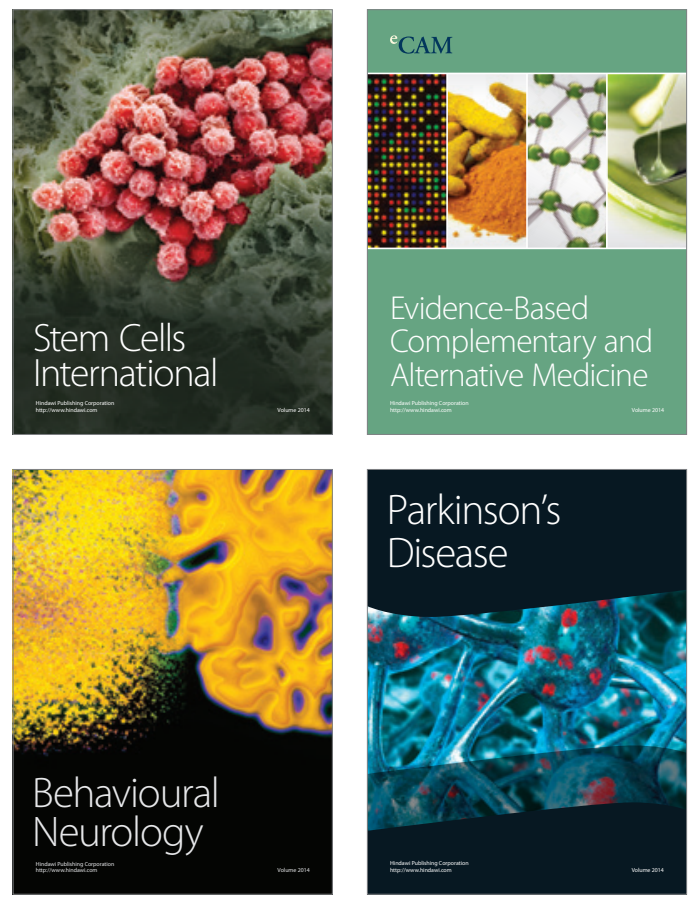
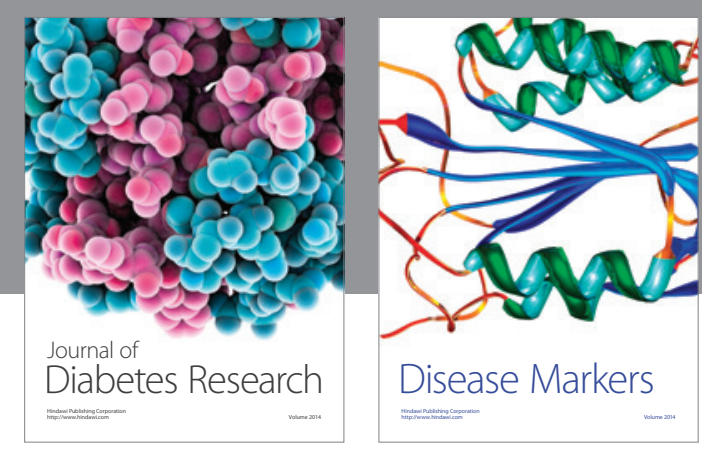

Disease Markers
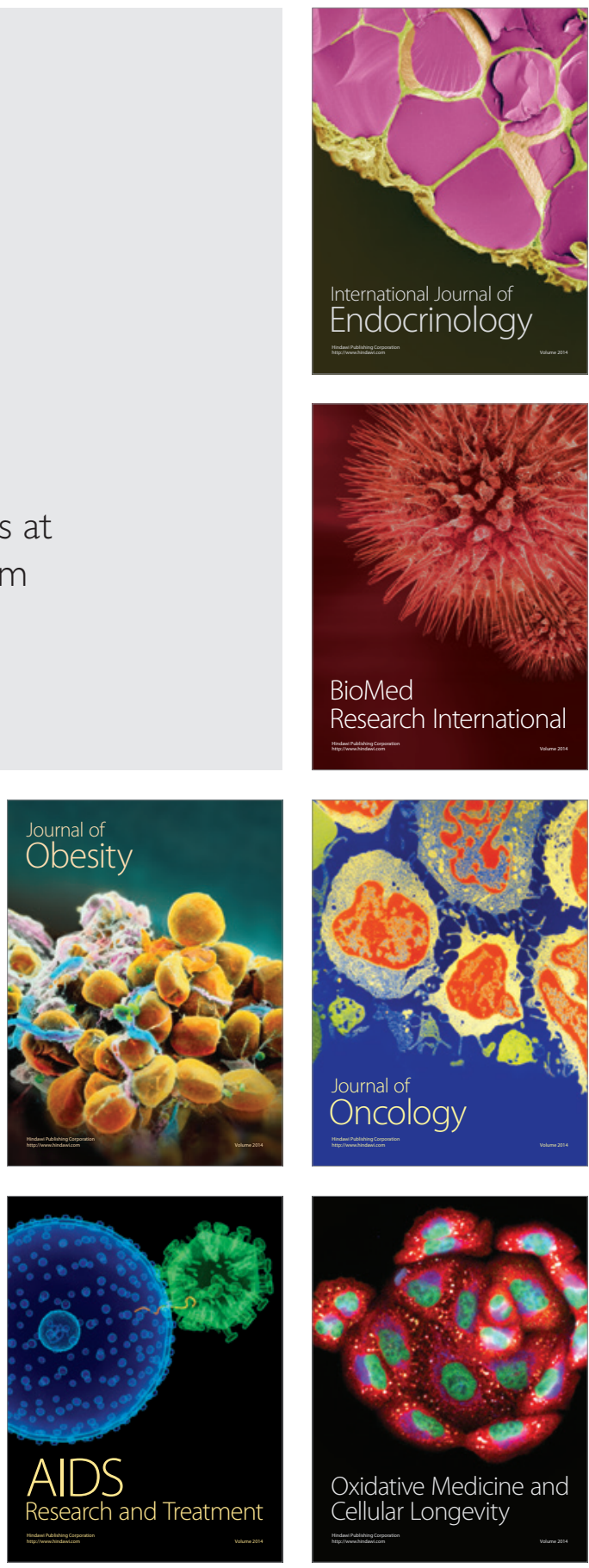